\title{
Notes on the vocalizations of Northern Hepatic-tanager (Piranga hepatica), Highland Hepatic-tanager (Piranga lutea) and Lowland Hepatic-tanager (Piranga flava)
}

Peter Boesman

In the following we briefly analyze and compare voice of the different races of Northern Hepatic-tanager (Piranga hepatica), Highland Hepatic-tanager (Piranga lutea) and Lowland Hepatic-tanager (Piranga flava). We also try to quantify the extent of any vocal differences using the criteria proposed by Tobias et al. (2010), as a support for taxonomic review. We have made use of sound recordings available on-line from Xeno Canto (XC).

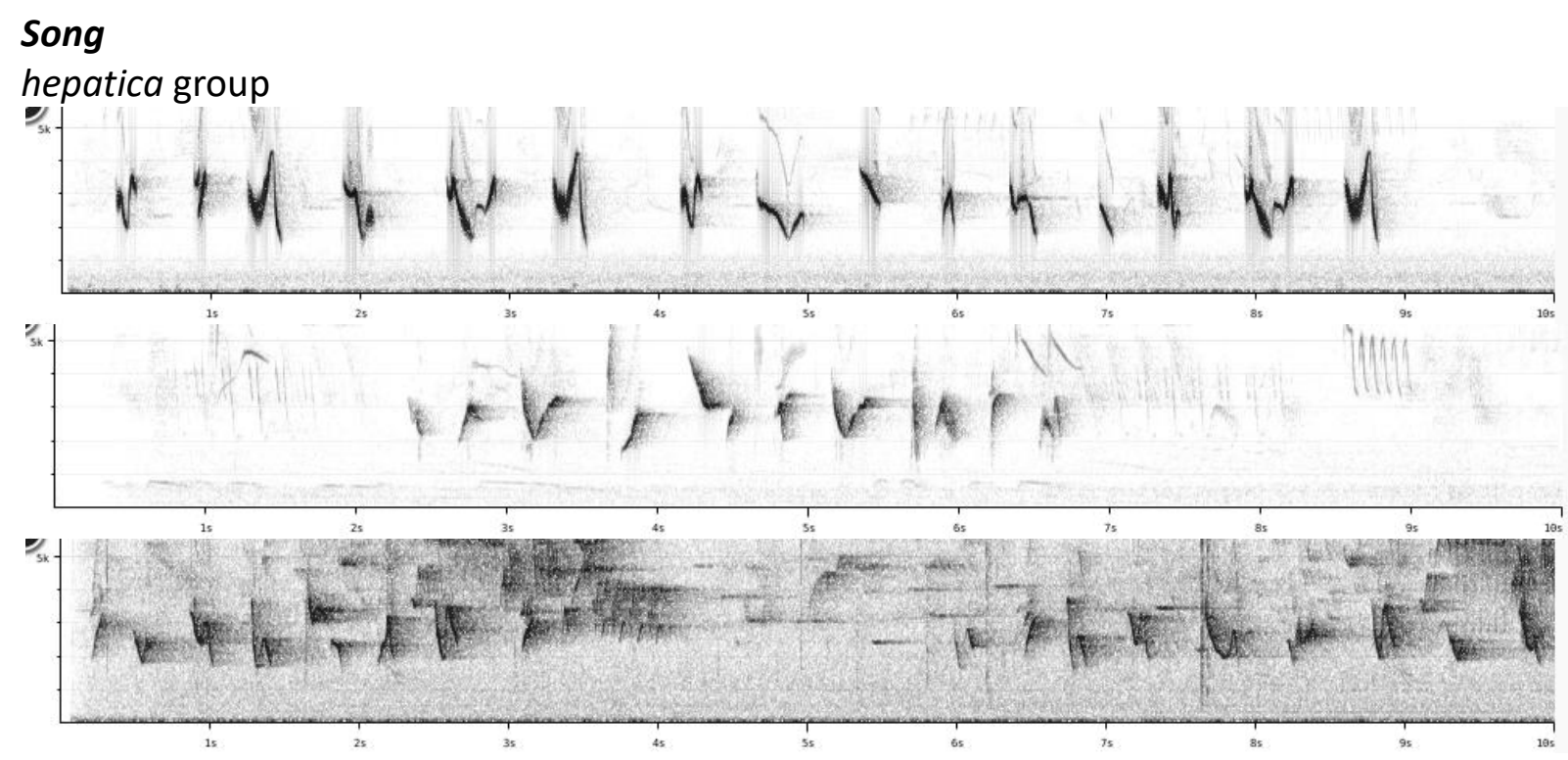

lutea group




HANDBOOK OF THE

BIRDSPIJUE WORLD

\section{ORNITHOLOGICAL NOTES}

flava group

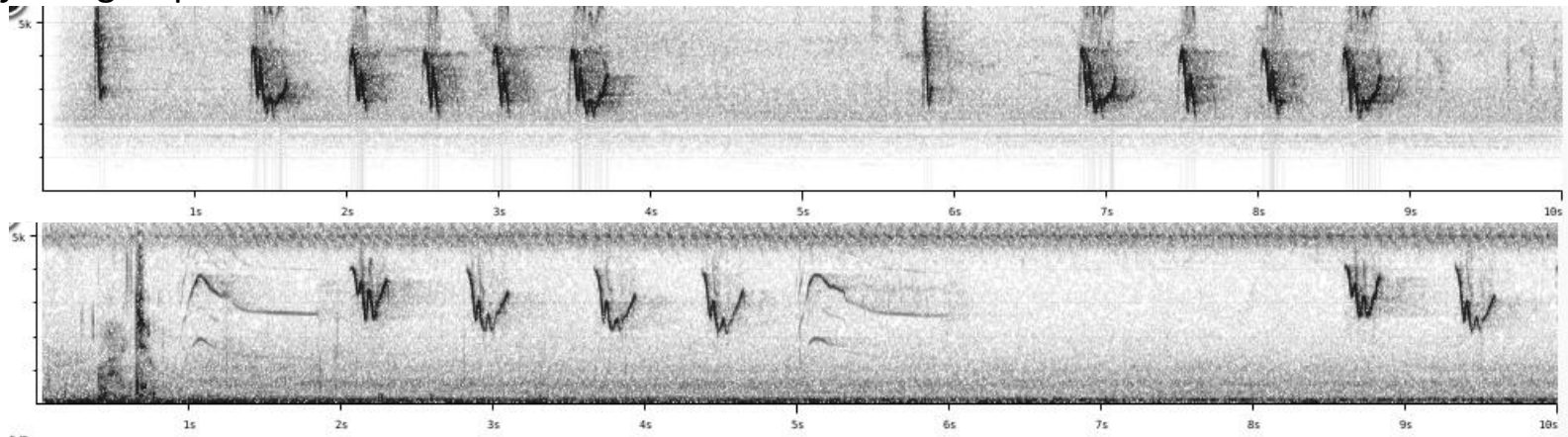

\section{Calls}

hepatica group

"chup" call
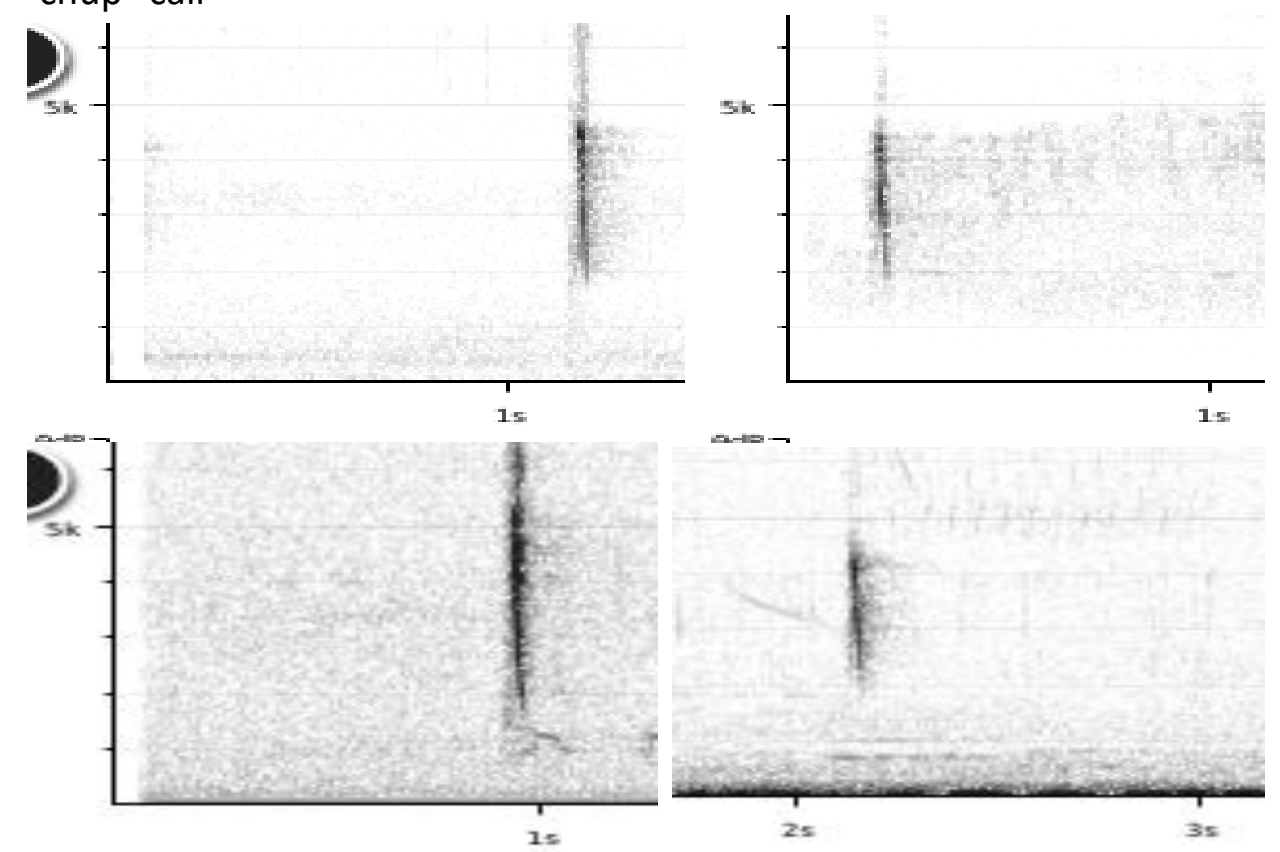

lutea group

"chup" call
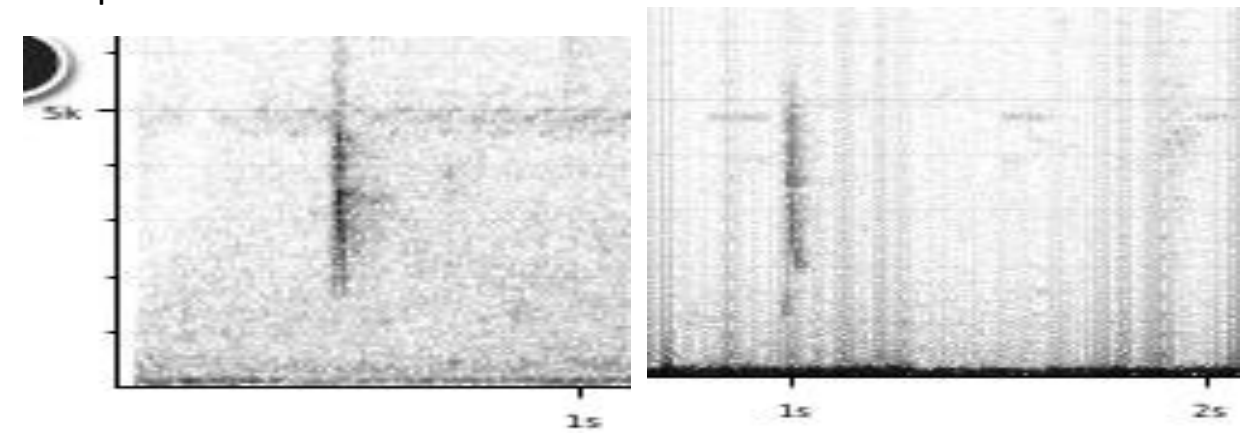


\section{HANDBOOK OF THE \\ BIRD S PF/THE WORLD}

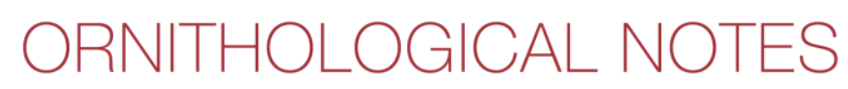

race testacea (lutea group) seems to be the only one that commonly utters a salvo of 3-4 chup calls:

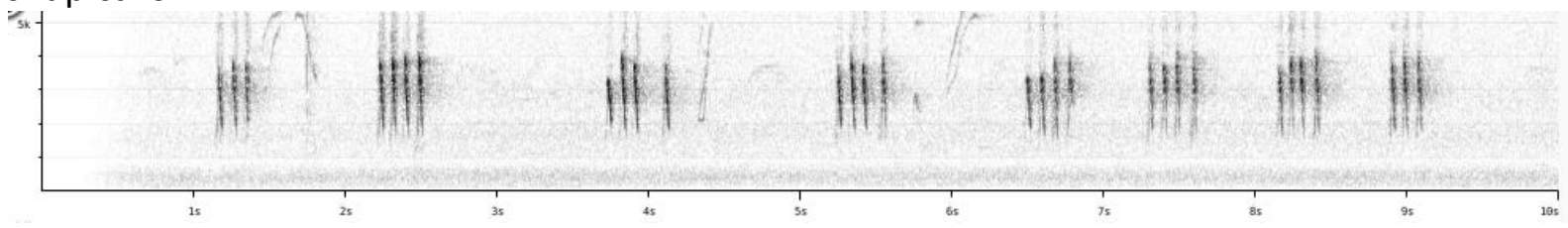

flava group

"cheep" call
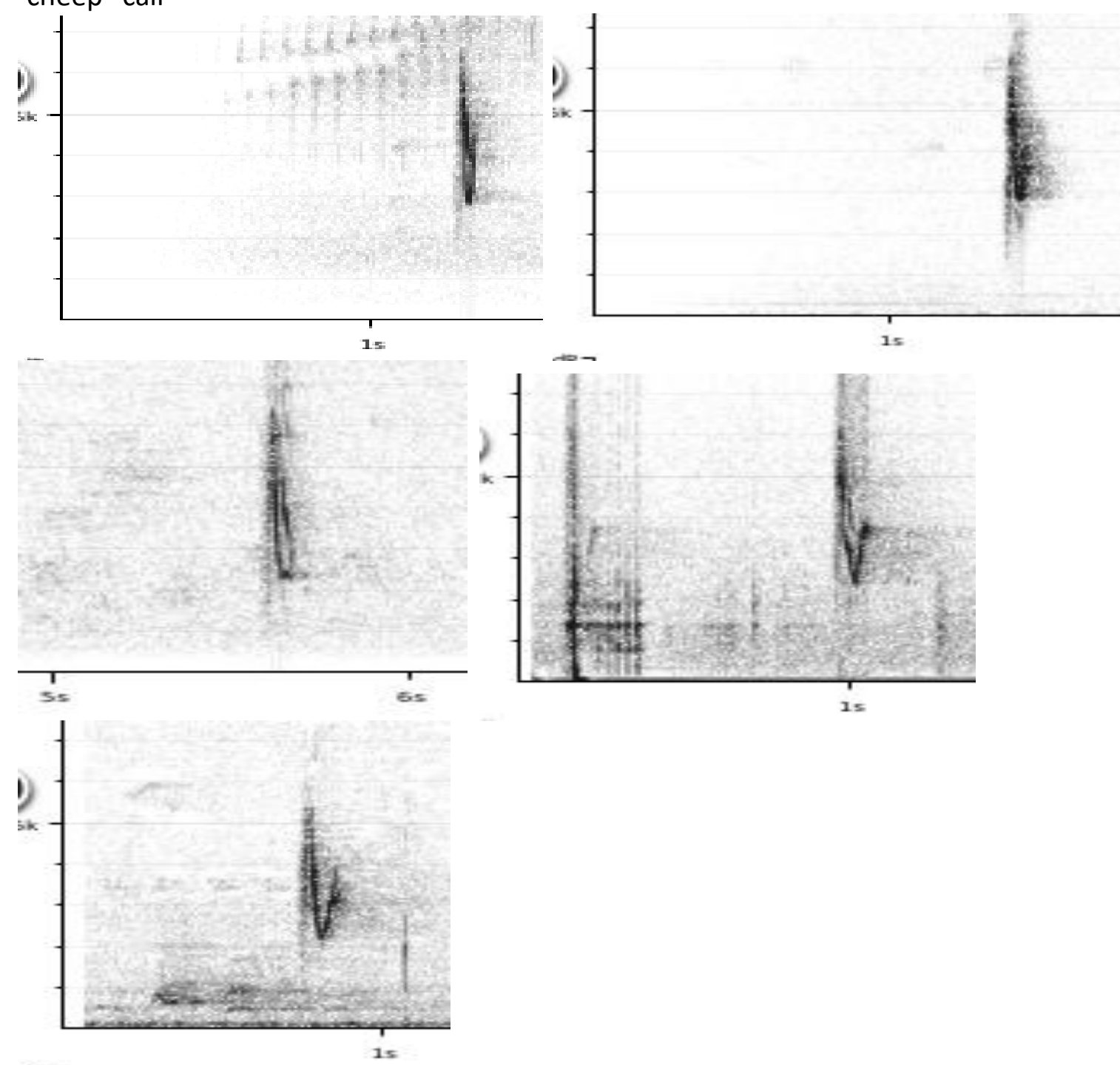

Song of flava group seems to have the most complex-shaped notes, lacking any simplershaped notes. Many notes are complex underslurred, and apparently there is little variation in note shape (few different note shapes), unlike other races.

Call of flava group is also clearly different, having an upslurred ending, while both other groups are about identical, having a very sharp upturned V-shape . 

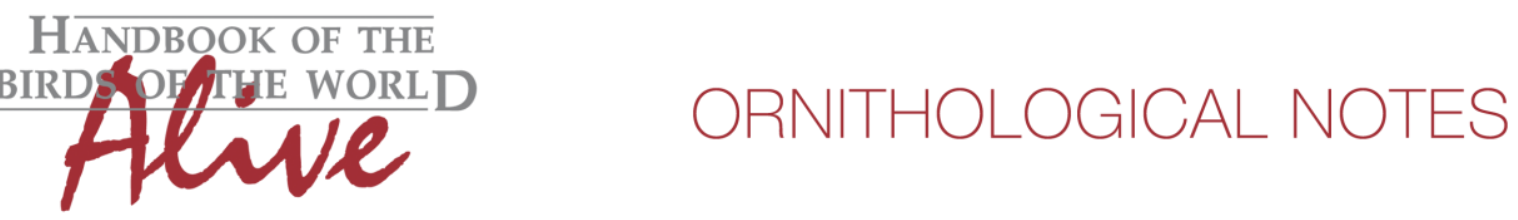

flava group thus vocally most distinct. A score of about 2-3 can be given in comparison with all other races for song (based on the number of different note shapes in an entire song baud) and a score of about 3 for call (based on end frequency of call note).

The two other groups have less obvious vocal differences. A more in depth analysis would be needed to uncover any vocal differences among these.

This note was finalized on 29th June 2016, using sound recordings available on-line at that moment. We would like to thank in particular the many sound recordists who placed their recordings for these species on $\mathrm{XC}$.

\section{References}

Tobias, J.A., Seddon, N., Spottiswoode, C.N., Pilgrim, J.D., Fishpool, L.D.C. \& Collar, N.J. (2010). Quantitative criteria for species delimitation. Ibis 152(4): 724-746.

\section{Recommended citation}

Boesman, P. (2016). Notes on the vocalisations of Northern Hepatic-tanager (Piranga hepatica), Highland Hepatic-tanager (Piranga lutea) and Lowland Hepatic-tanager (Piranga flava). HBW Alive Ornithological Note 386. In: Handbook of the Birds of the World Alive. Lynx Edicions, Barcelona. (retrieved from http://www.hbw.com/node/1252943 on 30 November 2016). 